\title{
Relation Between Inflammatory Indices and The Outcome of Meconium Aspiration Syndrome
}

MOHAMED ABDELALL MOHAMED 1, MOSTAFA ASHRY MOHAMED 2 , Diana YousriArmanious3.

1-Professor of pediatrics, Faculty Of Medicine, Sohag university, Sohag, Egypt. 2- Lecturer Of pediatrics, Faculty Of Medicine, Sohag university, Sohag, Egypt. 3-Specialist, Pediatrics Department, Faculty Of Medicine, Sohag university, Sohag, Egypt.

Type of article: Original

\section{Abstract:}

Background: Meconium aspiration syndrome (MAS) is linked to inflammation,but data on the patterns of hematologica indices and C-reactive protein (CRP) in MAS are lacking The aim of the study was to evaluate CRP, white blood cell count (WBC), absolute neutrophil count (ANC), and procalcitonin in

MASandtoassesstheirassociationwithdiseaseseverity.

Methods: a prospective hospital based studyincluding 200 babies admitted in this period with MSAF, among those 50 babies have meconium aspiration syndrome (25 males) Recruited neonates were 1-7 days old with range of weight from 2 to $3.9 \mathrm{~kg}$

Results: all the inflammatory indices were markedly elevated in cases of MAS with septicemia in comparison with cases of MAS without septicemia, maximum CRP, and maximum PCT values were higher in neonates with very sever and sever MAS compared to non sever MAS. PCT and CRP correlated with duration of mechanical ventilation, duration of any respiratory support and length of hospital stay. PCT more sensitive rather than other inflammatory indices.

Keywords: :white blood cell count; absolute neutrophil count;procalcitonin and CRP.

\section{Introduction:}

Meconium aspiration syndrome (MAS) is a common cause of severe respiratory distress in term infants, with an associated highly variable morbidity and mortality. MAS results from aspiration of meconium during intrauterine gasping or during the first few breaths. Meconium aspiration into the lungs induces intense inflammatory response with polymorphonuclear cells infiltration diffusely throughout the lungs. Signs include tachypnea, nasal flaring, retractions, cyanosis, greenish yellow staining of umbilical cord, nail beds, or skin , underlying physiologic stressors also may contribute. If complete bronchial obstruction occurs, atelectasis results, partial blockage leads to air trapping on expiration, resulting in hyper expansion of lungs and possibly pulmonary air leak with pneumomediastinum or pneumothorax.Persistentpulmonary hypertension can be associated with meconium aspiration as a comorbid condition or because continuing hypoxia.(Singh BS, 2009).

Meconium stores various substances including cytokines such as interleukin (IL )- IB , IL-6 ,IL-8, tumor necrosis factor, and thus constitutes a potent inducer of chemical pneumonitis. while previous studies have connected increased cytokine levels to MAS in vivo and in vitro, data on the most commonly used inflammatory indices in clinical practices namely hematological parameters and 
C- reactive protein (CRP) are sparse. (De Beaufort AJ,2003).

Procalcitonin concentrations increase within 2 hours of an infectious episode, peak at 12 hours, and normalize within 2 to 3 days in healthy adult volunteers A physiologic increase in procalcitonin concentration occurs within the first 24 hours of birth, and an increase in serum concentrations can occur with noninfectious conditions (eg, respiratory distress syndrome).

(Chiesa C, 2003).

The aim of the present study is;

(I) Characterize patterns of CRP, CBC

(white blood cell count) (WBC),

absolute neutrophil ratio (ANC), (ESR), procalcitonin in neonates with

meconium aspiration syndrome during the first week of life,

And,

(II) To analyze the relationship between inflammatory indices and illness

severity.

Material and methods:

This was a prospective hospital based study taking place at Sohag university hospital. All full term and post term neonates admitted to neonatal unit of Sohag university hospital with meconium aspiration syndrome in period from October 2016 to September 2017 were included to the study. Preterm neonates, neonatal TTN and with hyaline membrane disease were excluded.

A total of 200 babies admitted in this period with MSAF, among those 50 babies have meconium aspiration syndrome (25 males). Recruited neonates were 1-7 days old with range of weight from 2 to $3.9 \mathrm{~kg}$.

\section{Results:}

This study was carried out in neonatal unit of Sohag university hospital in period from October 2016 to September 2017 and included 200 babies admitted in this period with MSAF, among those 50 babies have meconium aspiration syndrome (25 males). Recruited neonates were 1-7 days old with range of weight from 2 to $3.9 \mathrm{~kg}$.
Blood samples were collected into sterile Vacutainer plastic tube (BD, Becton Dickinson, USA) and divided as follow;

$1-3 \mathrm{ml}$ Blood in K3 EDTA (TriPotassium EDTA) for Complete Blood Count (CBC), total (WBCs) and absolute neutrophil count.

2-2ml Serum for CRP by Red Cap Tubes.

$3-3 \mathrm{ml}$ blood in $\mathrm{K} 3$ EDTA in Westergren tube for ESR.

4- $2 \mathrm{ml}$ Serum sample for PCT by Vidas.

\section{Statistical Analysis:}

Data was analyzed using STATA intercooled version 12.1. Quantitative data was represented as median and range. Test for trend was used to compare qualitative data. Qualitative data was presented as number and percentage. Correlation analysis was done using spearman correlation test. Roc curve analysis was used to detect best cutoff of different inflammatory indices that predict very severe MAS. Sensitivity, specificity, positive predicted value and negative predictive value were also calculated. Odds ratios were obtained from logistic regression analysis. Graphs were produced by using Excel or STATA program. P value was considered significant if it was less than 0.05 .

Ethics of research:The aim of the study will be explained to each participate before collection of the data. Verbal consent will be obtained from those who welcome to participate in the study.Privacy of all the data will be assured. 
( Table 1) Outcome of studied populations

\begin{tabular}{|l|l|}
\hline Variable & Summary statistics \\
\hline Duration in NICU & \\
Mean \pm SD & $12.62 \pm 10.74$ \\
Median (range) & $8(3-45)$ \\
\hline Duration on mechanical ventilation & $8.48 \pm 11.79$ \\
Mean \pm SD & $4(0-45)$ \\
Median (range) & \\
\hline Duration on oxygen & $2.92 \pm 1.50$ \\
Mean \pm SD & $3(0-7)$ \\
Median (range) & \\
\hline
\end{tabular}

This table demonstrates the outcome of neonates with MAS and duration of admission in NICU, The median range of admission at NICU was 8 days, median range of mechanical ventilator was 4 days and median duration of oxygen therapy was 3 days.

Neonates were grouped according to severity of MAF into:

Neonates with not sever MAS who didn't need respiratory support, or only need non invasive respiratory support.

Neonates with sever MAS who needed invasive mechanical ventilation for less than 7 days without the need for HFO.

Neonates with very sever MAS who needed invasive mechanical ventilation for more than 7 days with the need for HFO.

( Figure 1) Distribution of severity of MAS among studied populations

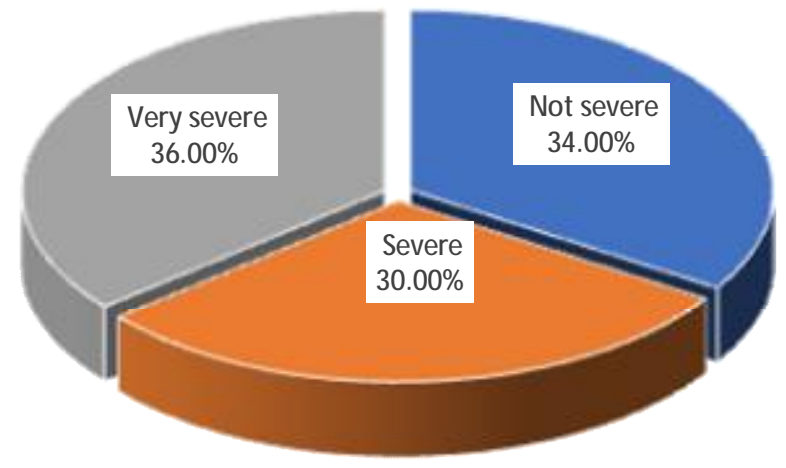

This figure demonstrates distribution of severity of MAS, very sever $36 \%$, sever $30 \%$ and not sever $34 \%$.

( Table 2) Relation between MAS with and without sepsis and inflammatory indices

\begin{tabular}{|l|l|l|l|}
\hline Variable & No sepsis & Sepsis & P value \\
\hline CRP & $24(6-48)$ & $48(12-96)$ & $<0.0001$ \\
\hline PCT & $10(0.9-60.4)$ & $25(1.8-60)$ & 0.001 \\
\hline ESR & $7(2-15)$ & $15(5-89)$ & $<0.0001$ \\
\hline WBCs & $8000(4000-18000)$ & $19000(10000-41000)$ & $<0.0001$ \\
\hline Neutrophilia (\%) & $39.3(22.4-79.4)$ & $73.8(55-89)$ & $<0.0001$ \\
\hline
\end{tabular}

Data was represented as median (range)

As shown in the previous table, All the inflammatory indices were markedly elevated in cases of MAS with septicemia in comparison with cases of MAS without septicemia. 
(Table 3) Prediction of Very Severe MAS with Inflammatory Indices

\begin{tabular}{|c|c|c|c|c|c|c|c|c|}
\hline Variables & AUC & Cut-off & $\begin{array}{l}\text { Sensitivity } \\
(\%)\end{array}$ & $\begin{array}{l}\text { Specificity } \\
(\%)\end{array}$ & $\begin{array}{l}\text { PPV } \\
(\%) \\
\end{array}$ & $\begin{array}{l}\text { NPV } \\
(\%) \\
\end{array}$ & $\begin{array}{l}\text { OR } \quad(95 \% \\
\text { interval })\end{array}$ & $P$ value \\
\hline CRP & $\begin{array}{l}0.87(0.74- \\
0.95)\end{array}$ & $>\mathbf{2 4}$ & $83.3(58.6-96.4)$ & $78.12(60.0-90.7)$ & $\begin{array}{l}68.2 \\
81.0)\end{array}$ & $\begin{array}{l}89.3 \\
96.0)\end{array}(74.5-$ & $17.9(3.99-79.74)$ & $<0.0001$ \\
\hline PCT & $\begin{array}{l}0.91(0.73- \\
0.97)^{(2)}\end{array}$ & $>15$ & $94.4(72.7-99.9)$ & $81.2(63.6-92.8)$ & $\begin{array}{l}73.9 \\
85.5)\end{array}$ & $\begin{array}{l}96.3(79.3- \\
99.4)\end{array}$ & $73.67(8.13-667.2)$ & $<0.0001$ \\
\hline ESR & $\begin{array}{l}0.87(0.75- \\
0.95)\end{array}$ & $>8$ & $88.9(65.3-98.6)$ & $68.7(50.0-83.9)$ & $\begin{array}{l}61.5 \\
73.3)\end{array}$ & $\begin{array}{l}91.7(74.5- \\
97.6)\end{array}$ & $17.6(3.38-91.56)$ & 0.001 \\
\hline WBCs & $\begin{array}{l}0.88 \\
0.95)\end{array}$ & $>1300$ & $88.9(65.3-98.6)$ & $78.1(60.0-90.7)$ & $\begin{array}{l}69.6 \\
81.8)\end{array}$ & $\begin{array}{l}92.6 \\
97.9)\end{array}$ & $28.57(5.26-155.17)$ & $<0.0001$ \\
\hline Neutrophilia (\%) & $\begin{array}{l}0.86(0.73- \\
0.94)\end{array}$ & $>55$ & 94.4 (72.7-99.9) & $71.9(53.3-86.3)$ & $\begin{array}{l}65.4(51.8- \\
76.9)\end{array}$ & $\begin{array}{l}65.4(51.8- \\
76.9)\end{array}$ & $43.4(5.0-376.3)$ & 0.001 \\
\hline $\begin{array}{l}\text { Any marker indicate } \\
\text { MAS }\end{array}$ & & & $100(81.5-100)$ & $43.75(26.4-62.3)$ & $\begin{array}{ll}50 & (32.9- \\
6.7) & \\
\end{array}$ & $\begin{array}{l}100 \quad(76.8- \\
100)\end{array}$ & Can't calculated & \\
\hline $\begin{array}{l}\text { All marker in } \\
\text { dicate MAS }\end{array}$ & & & $72.2(46.5-90.3)$ & $96.9(84.8-99.9)$ & $\begin{array}{l}92.9 \\
99.8)\end{array}$ & $\begin{array}{l}86.1 \\
95.3)\end{array}$ & $80.6(8.6-759)$ & $<0.0001$ \\
\hline
\end{tabular}

$\mathrm{CI}=$ confidence intervals. OR indicates the odds of very severe MAS comparing predictor values above and below the indicated cut-off

By analysis of values obtained during first 7 days of life, maximum CRP, and maximum PCT values were higher in neonates with very sever and sever MAS compared to non sever MAS. PCT and CRP correlated with duration of mechanical ventilation, duration of any respiratory support and length of hospital stay. PCT more sensitive rather than other inflammatory indices.

Roc curve comparing different indices for prediction of Very Severe MAS

(Figure 2)

This figure demonstrates that different inflammatory indices affect outcome of cases of MAS and PCT was more sensitive than others with Roc area 0.91 .

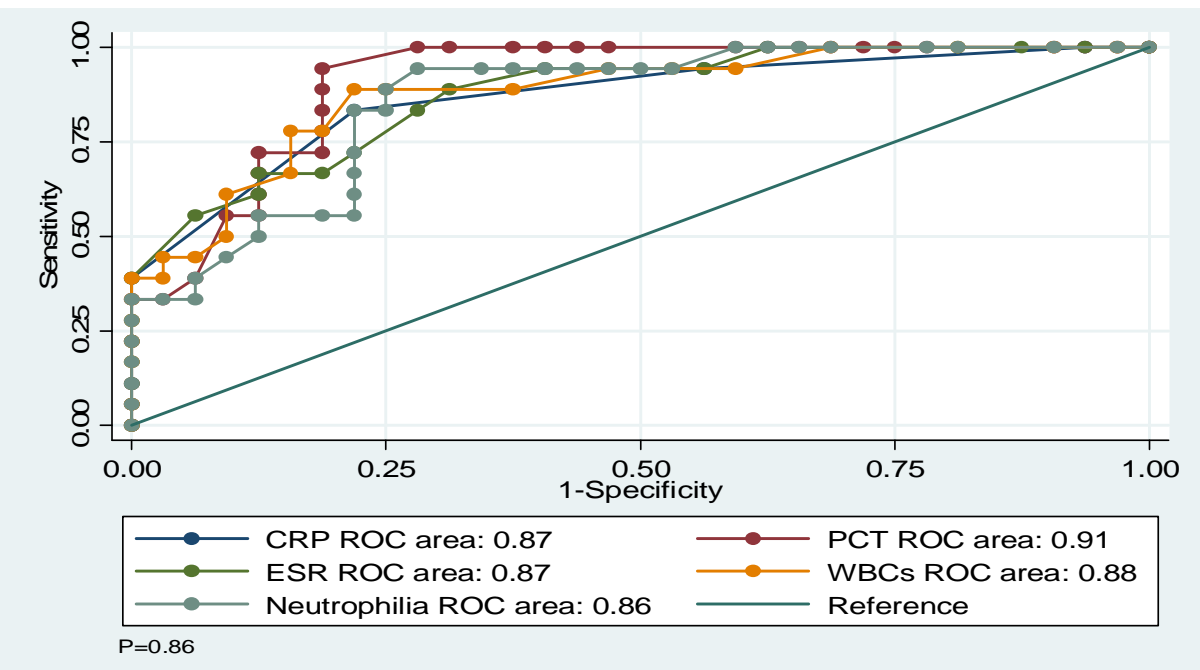

\section{Discussion}

Many studies were conducted in an attempt to correlate between the severity of neonatal sepsis and/ or respiratory distress disorders in neonates in one hand and many inflammatory indices such as ANA, WBCs, CRP, ESR, in the other hand. (Hofer N, Jank K, 2016).

Meconium aspiration is still a problem for significant neonatal morbidity 
despite great advances in neonatal medicine. It is very common problem in Egypt. Unfortunately, there is no reliable source of information providing national annual estimate. Therefore neonatal MAS deserves more research. Recent studies suggest that avoidance of post -term delivery may reduce the risk of intrauterine hypoxia and the incidence of MAS.

The aim of the present study is to characterize patterns of CRP, CBC (white blood cell count) (WBC), absolute neutrophil ratio (ANC), (ESR), procalcitonin in neonates with meconium aspiration syndrome during the first week of life andto analyze the relationship between inflammatory indices and illness severity.

our study revealed that WBCs, neutrophil count and ESR were more increased in cases with MAS and with sepsis rather than cases with MAS without sepsis as (table 2).

In this study, non severe MAS resemble $34 \%$ of cases, Sever MAS resemble $30 \%$ of cases and Very sever MAS resemble $36 \%$ of cases as (Figure 1).

The outcome of neonates with MAS and duration of admission in NICU , The median range of admission at NICU was 8 days, median range of mechanical ventilator was 4 days and median duration of oxygen therapy was 3 days as (table 1).

Diagnostic accuracy of the inflammatory indices to discriminate between

Very severe and non-severe MAS within the first 7 days of life is shown in table (3) and figure (2).

All indices being above or below the cut-off values obtained by ROC analysis , CRP roc area (0.87), ESR Acknowledgement: Authors thank colleges in the Pediatric Department, Faculty

Of Medicine, Sohag University, Egypt for their assistance and the roc area (0.87), Neutrophilia roc area (0.86), WBCs roc area $(0.88)$ and PCT roc area (0.91).

The same results were documented in the study of (Tripathi S, Saili A,Dutta $\mathbf{R , 2 0 0 7}$ ), in which there was relation between increase different inflammatory markers indices as WBCs, ANC and ESR and increase severity of MAS.PCT was more sensitive than other inflammatory markers.

Similar result was that of (Simon $\mathbf{L}$ and Gauvin F,2004),

they observed that serum PCT rapidly normalized after effective treatment. Thus, so PCT sampling helps to detect disease more quickly and is more sensitive than CRP level.

\section{conclusion:}

High CRP and PCT, ESR, WBC and ANC values were closely linked to disease severity in MAS. Though the inflammatory indices were able to predict illness severity during very early phases of the disease, the usefulness of this finding has still to be proven in clinical practice. However, results highlight the role of inflammation in the pathogenesis of MAS and its association with disease severity. Presence of sepsis increase severity of MAS and lead to more complications.

Our study revealed that cases of MAS with sepsis need more duration in NICU , more on MV and more O2 support due to increase severity of MAS than cases without sepsis.

Also this study revealed that PCT sampling helps to detect disease more quickly and is more sensitive than other inflammatory markers. 
parents of neonates who participated in this study.

Authors contribution: All authors contributed to this project and article equally. All authors read and approved the final manuscript.

\section{REFERENCES:}

1-Ahanya SN, Sureshbabu N, Morgan BL, Ross MG, Meconium passage in utero: mechanisms, consequences and management. ObstetGynecolSurv. 2005;60(1):45-65.

2- Altunhan H, Annagür A, Örs R et al, Procalcitonin measurement at 24 hours of age may be helpful in the prompt diagnosis of early-onset neonatal sepsis. Int. J. Infect. Dis. 2011; 15: e854-858.

3-Angert RM ,Pilon AL, Chester D, Reduces inflammation in meconium aspiration syndrome. Ann Trop Paediatr 2007;27:107-13.

4- Ameta G, Upadhyay A, Gothwal S, Singh K, Dubey K, Gupta A, Role of gastric lavage in vigorous neonates born with meconium stained amniotic fluid. Indian J Pediatr. 2013;80(3):195198.

5- Amro K, Usefulness of C-reactive protein in diagnosis of intrapartum and postpartum neonatal sepsis. Sudan Journal of Medical Sciences 2008;3 :233-238.

6-Balchin I, Whittaker JC, Lamont RF, Steer PJ, Maternal and fetal characteristics associated with meconium-stained amniotic fluid. Obstet Gynecol. 2011: 117(4):828-35.

7- Baquero H, Soliz A, Neira F, Venegas ME, Sola A, Oral sildenafil in infants with persistent pulmonary hypertension of the newborn: a pilot randomized blinde study. Pediatrics 2006; 117: 1077-1083.

8-Barratt-Due A, Pischke SE, Brekke OL, Thorgersen EB, Nielsen EW, Espevik T, Huber-Lang M, Mollnes TE, Bride and groom in systemic inflammation - the bells ring for complement and Toll in cooperation. Immunobiology 2012;217:10471056.
9-Basu B, Sinha SK ,Basu T ,Mahapatra TK, Factors predicting mortality in newborn ventilation .pediatrpulmonol 2015:50:271.

10- Basu S, Kumar A, Bhatia BD. Role of antibiotics in meconium aspiration syndrome . Ann Trop Pediatr 2007;27:107-13.

11-Becker KL, Snider R, Nylen ES, Procalcitonin assay in systemic inflammation, infection, and sepsis: Clinical utility and limitations. Crit Care Med. 2008;36:941-952.

12 -Benitz WE., Adjunct laboratory tests in the diagnosis of early-onset neonatal sepsis. Clin. Perinatol. 2010; 37: 421438.

13-Bergamini CM, Gambetti S, Dondi A, Cervellati C, Oxygen, reactive oxygen species and tissue damage. Curr Pharm Des 2004;10:1611-1626.

14-Bouadma L, Luyt CE, Tubach F et al , Use of procalcitonin to reduce patients' exposure to antibiotics in intensive care units (PRORATA trial): A multicentrerandomised controlled trial. Lancet 2010; 375: 463-474.

15-Brown KL,Striam S, Ridout D, CassidyJ, Pandya H, Liddell M, Davis C, Goldman A, Field D , Karimova A , Extracorporeal membrane oxygenation and term neonatal respiratory failure deaths in the United Kingdom compared with the United States:1999-2005. PediatrCrit Care Med 2010:11:60-65.

16 -Carbine DN, Meconium aspiration .Paediatr Rev2008;29:212-3.16

17-Castellheim A, Pharo A, Fung M, Saugstad OD, Mollnes TE, Complement C5a is a key mediator of meconium-induced neutrophil activation. Pediatr Res 2005;57:242247.

18- Cayabyab RG, Kwong K, Jones C, Minoo $P$, Durand $M$, Lung inflammation and pulmonary function in infant in infants with meconium aspiration. Pediatrpulmonol 2007;42:898-905.

19-Chacko B, Sohi I, Early onset neonatal sepsis . Indian $\mathbf{J}$ Pediatr 2005;72:23-26. 
20-Chettri S, Adhisivam B, Bhat BV, Endotracheal suction for non vigorous neonates born through meconium stained amniotic fluid: a randomized controlled trial. $J$ Pediatr. 2015;166(5):1208-1213.

21-Chiesa C, Natale F, Pascone R, et al, $C$ reactive protein and procalcitonin; reference intervals for preterm and term newborns during the early neonatal period.ClinChimActa. $\quad 2011 ; 412(11-$ 12):1053-1059.

22 -Chiesa C, Pellegrini G, Panero A, Osborn JF, Signore F, Assumma M, et al, C-reactive protein, interleukin-6, and procalcitonin in the immediate postnatal period: influence of illness severity, risk status, antenatal and perinatal complications, and infection. Clinical Chemistry. 2003;49(1):60-8.

23- Christensen, R. D., Henry, e., Jopling, J., \&Wiedmeier, S. E, The CBC: Reference ranges for neonates. Pediatr Res. 2009:33,3-11.

24-Dargaville PA, Respiratory support in meconium aspiration syndrome: A practical guide. Int $J$ Pediatr. 2012;2012:965159.

25 -Dargaville PA, Copnell B, The epidemiology of meconium aspiration syndrome: incidence, risk factors therapies, and outcome. Pediatrics 2006: 117 : $1712-1721$. 
SOHAG MEDICAL JOURNAL Relation Between Inflammatory Indices 